\title{
REPRESENTAÇÕES SOCIOEDUCATIVAS DA PRISÃO
}

Flavio Antônio Manfrin ${ }^{1}$

\section{RESUMO}

Este artigo é o resultado de uma pesquisa que teve como objetivo analisar o Programa de Educação de Jovens e Adultos (EJA) na Penitenciária Agrícola de Chapecó (PACH) como medida socioeducacional. O tema se embasa no desafio de promover a Educação de Jovens e Adultos em espaços de privação de liberdade, levando em consideração aspectos relacionados aos direitos constitucionais de acesso à educação, direitos humanos e as diretrizes educacionais para a educação prisional.

Palavras-chave: Educação. Socioeducacional. Programa EJA.

\section{SOCIOEDUCATIONAL REPRESENTATIONS OF PRISON}

\begin{abstract}
This article is the result of a research that had as objective to analyze the Program of Education of Young and Adults (EJA) in the Agricultural Penitentiary of Chapecó (PACH) as a social and educational measure. The theme is based on the challenge of promoting youth and adult education in places of deprivation of liberty, taking into account aspects related to the constitutional rights of access to education, human rights and educational guidelines for prison education.
\end{abstract}

Keywords: Education. Social and educational. EJA program.

\footnotetext{
${ }^{1}$ Bacharel em Administração (UNOESC), Especialista em Gestão Empresarial (UNOESC), Mestre em Políticas Sociais e Dinâmicas Regionais (UNOCHAPECÓ), Doutorando em Ciências Sociais (UNISINOS), aluno não regular. Gerente Administrativo da empresa educacional INFORMAR - Educação. Professor dos cursos de Administração, Recursos Humanos e Processos Gerenciais. Palestrante de temas voltados às politicas Públicas e Educação.
} 


\section{INTRODUÇÃO}

Este artigo apresenta dados de uma análise sobre as representações socieducativas no ambiente prisional, especificamente do Programa de Educação de Jovens e Adultos (EJA) na Penitenciária Agricola de Chapecó (PACH) como uma das configurações do campo socioeducacional. Considerando a educação, como medida socioeducativa de recuperação do criminoso.

Considerando a reintegração social do egresso do sistema prisional como um processo que requer atenção das instituições estatais responsáveis pela segurança pública, e no intuito de reduzir a reincidência ao crime, o Estado por meio do Departamento de Administração Prisional (DEAP), em parceria com órgãos educacionais dos Estados, procuram promover ações socioeducacionais, que possam, além de ocupar o tempo ocioso do detento, prepará-lo para sua reinserção na sociedade. Nas diversas ações socioeducacionais desenvolvidas nos presídios, o Programa de Educação de Jovens e Adultos (EJA), é o órgão local responsável por promover a qualificação profissional e tentar resgatar a escolarização dos detentos que não concluíram seus estudos no momento apropriado da vida.

$\mathrm{Na} \mathrm{PACH}$, o programa EJA é desenvolvido pelo Centro de Educação de Jovens e Adultos (CEJA) de Chapecó que está subordinado à Gerência de Educação (GERED) da Agência de Desenvolvimento Regional (ADR) e operacionalizado pela Gerência de Saúde, Ensino e Promoção Social (GSEPS) da PACH. Segundo o Sistema Integrado de Informações Penitenciárias - DEPEN, nos presídios brasileiros, a maioria dos presos não concluiu sequer o Ensino Fundamental.

Tendo em vista que o resgate educacional dos jovens e adultos se constitui em um direito constitucional, mesmo o indivíduo estando em situação de privação de liberdade, o acesso à educação, precisa ser garantido. Neste sentido, o Conselho Nacional de Política Criminal (CNPC) aprovou em 14 de maio de 2009, a resolução 03/2009, que estabelece, em seu art. $1^{\circ}$, as diretrizes nacionais para a oferta de educação nos estabelecimentos penais e definiu três eixos de atuação: a) gestão, articulação e mobilização; b) formação e valorização dos profissionais envolvidos na oferta de educação na prisão; e c) aspectos pedagógicos, considerando as especificidades do ambiente e as limitações encontradas na educação prisional. Nesse sentido, os Estados começaram um processo de adequação a essa normativa.

Mesmo a legislação garantindo o acesso a educação nos estabelecimentos penais, a efetivação das ações, está condicionada à estrutura física e administrativa de cada unidade. 
Fundado no exposto, surgem questionamentos sobre o funcionamento da escola e do programa educacional como medida socioeducativa dentro dos muros da prisão: Como se estrutura um programa de EJA dentro da prisão? Quais são as representações dos presos sobre a educação atrás das grades? Como se sentem os educadores ao se depararem com a escola prisional? Como a educação prisional pode contribuir para a ressocialização do criminoso? Portanto, considerando essas indagações, e, que a população carcerária é contingente relevante, inserida no contexto regional, presente na dinâmica social e um problema impactante no desenvolvimento socioeconômico. Justifica-se por si só, a relevância da temática.

Para buscar esclarecer as questões ora apresentadas, buscou-se, no estado da arte, trabalhos científicos desenvolvidos sobre o tema, os quais, se restringem a poucas produções específicas. Apesar da escassez de estudos nessa área, há publicações significantes sobre o assunto; destaca-se a coletânea de artigos dos organizadores Lourenço e Onofre (2012) intitulado "O espaço da prisão e suas práticas educativas: enfoques e perspectivas contemporâneas", publicada pela Editora da Universidade Federal de São Carlos, São Paulo (UFScar), que trata de alguns temas relacionados ao cotidiano prisional, como: a construção de conhecimentos empíricos e cultura carcerária.

Nesse sentido, considera-se a abordagem da segurança pública um problema que requer articulação sistêmica, institucional e social. Onde, as definições das políticas públicas deveriam estar voltadas à garantia dos direitos civis e construção da cidadania, como reza a Constituição Federal de 1988, no seu art. $1^{\circ}$, no qual prevê a igualdade entre os indivíduos sem a discriminação de qualquer natureza. Também, na LDB, está garantido o acesso à educação sem distinção de raça, cor, credo, classe social ou condição judicial, e na Lei de Execuções Penais, é reafirmado, que todo o preso tem o direito à educação, e sua oferta é dever do Estado. Desta forma, percebe-se, também, a educação como política de segurança pública de controle da criminalidade e reincidência.

Devido o crescente aumento da criminalidade, que causa insegurança e apreensão. O Conselho Nacional de Justiça (CNJ) publica em 2014 que a população carcerária brasileira vem aumentando vertiginosamente nos últimos anos, se constituindo em um dos maiores problemas da contemparaneidade..

O Brasil tem a quarta maior população carcerária no mundo, ranking liderado pelos Estados Unidos da América, seguido pela China $\left(2^{\circ}\right)$ e Russia $\left(3^{\circ}\right)$, mesmo os dois primeiros utilizando de um rigoroso sitema de punição baseado na violência, a situação não se reverte. No ranking do país, o Estado de Santa Catarina é o sétimo estado com maior 
população carcerária, com 16. 366 detentos Na Penitenciária Agícola de Chapecó (PACH), estão presos em torno de 1600 detentos, destes, 85 presos estão frequentando a escola prisional.

Com base nesses dados, buscam-se alternativas que venham diminuir a criminalidade e os altos índices de reincidência, para isso, o Estado procura implementar ações para cumprir as determinações estabelecidas na legislação e que foram ignoradas ao longo do tempo - a educação prisional como direito de todos os indivíduos privativos de liberdade. Para isso define a educação como uma ferramenta que possa contribuir na preparação do preso para o seu retorno ao convívio social, por meio do Programa de EJA nas unidades prisionais.

\section{Reflexões teóricas sobre o ambiente da educação prisional}

A educação está presente no cotidiano social, onde as relações de interação se tornam um terreno fértil de aprendizado, o qual fornece ao indivíduo subsídios que moldam seu comportamento e caráter. Em se tratando do convívio social, em qualquer ambiente em que o indivíduo esteja inserido, Piaget (1971) concebe a conduta humana como uma adaptação ou mesmo como uma contínua readaptação. A conduta é explicada como trocas funcionais entre o indivíduo e o meio exterior, em dois aspectos intimamente interdependentes: o cognitivo e afetivo. Nesse sentido que se buscam argumentos sobre o modo de educação dos indivíduos em regime de privação de liberdade. Inseridos em um sistema penal onde a conduta adotada se baseia na concepção arcaica de penalização pela violência.

Nesse sentido, para situar a educação no ambiente da prisão, precisa-se conhecer as relações que permeiam esse ambiente para isso, procuramos situar as relações do ambiente prisional sob a perspectiva de Michel Foucault e a educação problematizadora e revolucionária no enfoque de Paulo Freire, sem a pretensão de tecer análise comparativoconclusiva ou analogia rigorosa sobre o pensamento dos dois autores. O que se propõe é simplesmente apresentar uma pequena aproximação sobre algumas reflexões em torno das discussões sobre o tema.

\section{O ambiente prisional na perspectiva de Foucault}


Para compreender o ambiente prisional e as relações sociais do ambiente penitenciário, assim como a educação dos presos como meio de recuperação, estabelece-se uma análise a partir do pensamento crítico de Foucault quanto à eficiência do sistema prisional como instituição de recuperação de criminosos.

A contribuição de Foucault (2014) para este estudo está em sua visão sobre a estrutura do sistema penal e as relações de poder nela constituídos, visivelmente aparentes em sua hierarquia. A disciplina imposta pelos agentes e a submissão do detento às normas estabelecidas, regem as ações e atividades das unidades; ocorre todo o tipo de violência e abusos, mesmo que as instituições digam o contrário. Foucault (2014) contextualiza afirmando que opressor e oprimido fazem parte do amplo campo das relações sociais, independendo de classe social ou nível hierárquico de poder. Aborda também o controle através da disciplina e regras de comportamento, defendendo que a submissão do indivíduo o torna dócil e, consequentemente, obediente às leis - modelo presente até os dias de hoje.

O pensamento filosófico de Foucault (2014) remete a uma análise histórica das relações sociais: acredita-se que dominação e poder não sejam originários de uma única fonte, como o Estado ou classes dominantes, mas são exercidos em várias direções, numa dinâmica complexa. Segundo o autor, essas relações são necessariamente acompanhadas da criação do saber e vice-versa.

\section{A educação prisional no enfoque teórico de Paulo Freire}

Na visão de Freire (2001), educar é construir, é libertar o homem do determinismo, é percebê-lo como ser autônomo com capacidade de transformar o mundo. $\mathrm{O}$ conceito de "educação", segundo Martins (2004), sofreu influências do nativismo e do empirismo; o primeiro entendido como desenvolvimento das potencialidades, o segundo como apropriações de experiências. Portanto, a educação em seu sentido mais amplo representa tudo aquilo que pode ser feito para desenvolver o ser humano.

Assim sendo, se for pela convivência que o homem se educa, pressupõe-se que o ambiente, o contexto e as influências determinam sua educação. Com o exposto, pretende-se discutir como a educação pode contribuir para a apropriação do conhecimento, mesmo em se tratando do "ambiente-prisão".

Procuramos utilizar a teoria freiriana da educação para compreender a concepção de sujeito-ação e suas implicações no contexto social, fazendo correlações com o 
ambiente prisional e verificando, assim, como a teoria de Freire pode ser entendida no ambiente "antissocial", do presídio, bem como na representação do sujeito criminoso.

A visão de Freire (2014) quanto à realidade da educação no Brasil pode ser encontrada na concepção da educação bancária: o sujeito recebe o conhecimento, como uma forma de depósito, sem que ele seja contestado ou discutido. Por outro lado, a proposta da educação problematizadora e revolucionária, de libertação do ser humano, promove a transformação do oprimido em sujeito cognoscente e autor de sua própria história através da práxis como unificação entre ação e reflexão.

\section{O SISTEMA PENITENCIÁRIO E SUAS CONFIGURAÇÕES ESPACIAIS}

O Sistema Penitenciário procura estabelecer ações socioeducacionais como forma de controle do espaço da prisão e para isso estabelece um modelo disciplinar que venha de encontro aos objetivos do encarceramento como medida judicial de cumprimento das penas. Nesse sentido o DEAP estabelece as regras gerais e cada unidade aplica conforme sua realidade, considerando as especificidades de cada uma.

Cada unidade prisional possui peculiaridades que se configuram como uma "marca ${ }^{2} "$. Essas configurações são perceptíveis, adentrando ao ambiente da prisão e conhecendo o cotidiano das unidades. Nesse sentido, o sistema penal como um todo precisa estar preparado para atender a inúmeros propósitos, além do aprisionamento do criminoso, ou seja, precisa estar preparado para atender a todo o contexto jurídico e social a que está submetido cada um dos detentos. Para Lopes, Pires e Pires (2014, p. 120), o estabelecimento penal, conforme a sua natureza deverá contar em suas dependências com áreas e serviços destinados a dar assistência, educação, trabalho, recreação e prática esportiva.

\section{Configuração socioeducacional do trabalho}

Nas ações socioeducativas voltadas ao trabalho, o DEAP atua na orientação das unidades prisionais do estado aproveitando as potencialidades econômicas de cada região. Segundo informações obtidas em entrevista com o sujeito de pesquisa $\mathrm{C}^{3}$, na $\mathrm{PACH}$, "as ações socioeducativas permitem que os presos se ocupem de atividades educativas e laborais,

\footnotetext{
2 Conjunto de elementos culturais encontrados em uma determinada área em um determinado tempo (MICHAELIS, 2008).

${ }^{3}$ Coordenador de Educação da Penitenciária Agrícola de Chapecó.
} 
com o objetivo de reduzir as penas impostas pela justiça através da remissão e incrementar a renda da família com o dinheiro ganho com as atividades laborais." Muitos dos presos chegam à prisão sem nenhuma profissão; nesses casos, as ações socioeducativas proporcionam ao sentenciado a oportunidade de aprender uma profissão e seguir carreira quando cumprida sua pena - eles levam para a vida um ofício que pode ajudar em sua reintegração à sociedade.

Mesmo que o modelo de reintegração seja voltado ao trabalho, para os presos, a educação é algo que poderia ter mudado sua vida se tivesse frequentado a escola na idade apropriada.

\section{Iniciativas e experiências na educação prisional}

No Complexo Penitenciário da $\mathrm{PACH}$, a maioria dos presos exerce atividades laborais, e uma minoria se dedica aos estudos. Do contingente total dos presos, somente $16,15 \%$ frequentam a escola; e, destes, mais de $65 \%$ ainda não concluíram o Ensino Fundamental. Os outros $84,85 \%$ dos presos não estão estudando, não tem autorização do poder judiciário para frequentar a escola devido a sua situação criminal, ou não tem interesse em estudar (Sujeito de Pesquisa (C1), 2015).

Nessa perspectiva, percebe-se que grandes desafios emergem ao se organizar um sistema educacional prisional; existem dificuldades, mas também possibilidades num sistema que está sendo estruturado com experiências singulares nos estados, cidades e unidades prisionais pelo País. Portanto, o maior desafio está em implantar ações socioeducativas significativas que envolva as entidades educacionais e de segurança.

É notório que a educação perpassa pelo direito à assistência educacional e torna-se uma forma de preparar o indivíduo para o seu retorno ao convívio social, como normatiza a Constituição Federal no capítulo III em relação à educação: "Direito de todos e dever do estado e da família, será promovida e incentivada com a colaboração da sociedade, visando ao pleno desenvolvimento da pessoa, seu preparo para o exercício da cidadania e sua qualificação para o trabalho" (BRASIL, 2009).

O estado de Santa Catarina, por meio da Secretaria Estadual de Educação, com a parceria da Secretaria de Estado da Justiça e Cidadania (SJC), no ano de 2013, promoveu a discussão para a elaboração do Projeto Político Pedagógico (PPP) para a educação prisional, com o objetivo de "Oportunizar a inserção dos detentos no contexto educacional dentro das Unidades Prisionais buscando na educação a construção de novos conhecimentos e a 
reconstrução de conhecimentos já elaborados.” (SED, 2013). Mas, até o momento, nada de concreto ocorreu; as ações não passaram de alguns encontros temáticos para levantar sugestões dos profissionais da educação e da Secretaria de Estado da Segurança Pública e Cidadania sobre a organização escolar nas prisões. Nesse sentido a educação carcerária continua sendo regida pelas diretrizes da educação regular contidas na LDB e normalizada pelo Conselho Estadual de Educação.

\section{A estruturação do programa EJA na Penitenciária Agrícola de Chapecó}

O Estado de Santa Catarina conta com 46 unidades penitenciárias distribuídas pelas seis mesorregiões, destas 33 unidades possuem salas de aula destinadas para atividades educacionais e 13 unidades não possuem nenhuma sala para atividades escolares. Nas unidades que disponibilizam o atendimento educacional, o sistema penitenciário catarinense disponibiliza, atualmente, 71 salas de aula para atendimento aos alunos/presos (DEPEN, 2014).

Na unidade prisional de Chapecó (PACH), no ano de 2014, havia 89 alunos/presos matriculados no Programa EJA, representando 7,41\% do contingente de presos no regime fechado e semiaberto. Esses alunos estavam dispostos em quatro salas de aula, duas no regime fechado e outras duas no regime semiaberto (Sujeito de pesquisa (C1), 2015).

\footnotetext{
A estrutura física da escola na PACH é composta por quatro salas de aula, sendo duas para o regime fechado e duas para o regime semiaberto. No regime fechado estão estudando atualmente, em torno de 40 alunos e no regime semiaberto em torno de 20 alunos. Os presos que frequentam a escola, são os que possuem penas mais longas a cumprir, e geralmente possuem escolaridade muito baixa. Eles encontram na escola da prisão uma forma de concluir seus estudos, passar o tempo e obter o benefício da remissão de pena. (Sujeito de Pesquisa C1, Pesquisa PACH, 2016).
}

O público atendido pelo programa EJA na $\mathrm{PACH}$ se constitui de presos com média de idade entre 18 e 40 anos, em diferentes níveis de escolarização; segundo dados de arquivo do CEJA/CHAPECÓ (2015), até o momento, na PACH, 28 alunos/presos concluíram efetivamente o Ensino Fundamental, 10 alunos concluíram seus estudos pelo exame do ENCCEJA e cinco concluíram o Ensino Médio e nenhum preso cursa o Ensino Superior.

Os alunos que ingressam na escola prisional têm como principal objetivo a remissão ${ }^{4}$ da pena pelo estudo, que segundo a legislação pode ser obtida por meio da

\footnotetext{
4 “Art. 126. O condenado que cumpre a pena em regime fechado ou semiaberto poderá remir, por trabalho ou por estudo, parte do tempo de execução da pena (LEI No 12.433, DE 29 DE JUNHO DE 2011, BRASIL, 2011).
} 
frequência e notas escolares, leitura de obras literárias e trabalhos extraclasse, conforme norma técnica 2012/ MEC/MJ e a recomendação n. 44, de 26 de novembro de 2013.

Mas como a escola não se constitui somente de uma estrutura física bem aparelhada; o CEJA de Chapecó, em parceria com a coordenação da Gerência de Saúde, Educação e Promoção Social da $\mathrm{PACH}$, desenvolve todas as ações pedagógicas referentes à educação. Isso envolve todo o trabalho inicial de levantamento da demanda para definir os módulos a serem ofertados no ano letivo; de posse do levantamento da demanda, os professores trabalham na definição do currículo de acordo com o perfil dos alunos/presos que irão frequentar a escola, com base na matriz curricular do Ensino Regular definida pela Secretaria Estadual da Educação (SED/SC).

Para as turmas de EJA nos espaços de privação de liberdade, o sistema de matriz curricular é o de Ensino Presencial por Disciplina, seguindo o mesmo código e padrão de matriz utilizado nas demais turmas do CEJA, obedecendo às Resoluções do CEB/CNE N $3 / 2010$ e CEE/SC No 074/2010, que estabelecem o tempo e carga mínima e a metodologia integralmente presencial. (SED/SC, 2014).

Após definição dos módulos a serem ofertados no ano letivo, os alunos/presos efetivam suas matrículas de acordo com a "etapa" ou "fase" que estão aptos a cursar. Desta forma, eliminam as disciplinas, até concluir cada etapa/fase. Para progredir aos módulos seguintes, o aluno precisa obter um conceito mínimo de 6,0 na avaliação final; quem não alcançar esse conceito mínimo precisa repetir a etapa/fase (SEDSC, 2014). A conclusão dos módulos pode ser feita, também com a nota do ENEM e pelas provas do Exame Nacional para Certificação de Competências de Jovens e Adultos -ENCCEJA. Os alunos que frequentam a escola regular na prisão são acomodados em salas específicas, de acordo com o regime de prisão que estão enquadrados. No caso dos alunos do regime fechado, a sala é dividida por grades que separa o professor da turma.

Segundo relatos do sujeito de pesquisa (C1), as carteiras para os alunos/presos são construídas com um material resistente e pesado, e afixadas no piso para que não sejam arrancadas e utilizadas como armas na agressão aos colegas. Por motivo de segurança do docente, a sala de aula é dividida por uma grade que separa o professor da classe. Cada aula tem duração média de duas horas, dependendo da etapa, disciplina ou fase. O seu início geralmente é tumultuado, pois segue procedimentos de segurança que atrasam o começo das atividades. Primeiramente o professor passa a chamada dos alunos para a equipe de segurança, que busca, individualmente, os presos nos pavilhões; ao adentrarem a sala de aula, são-lhes tiradas as algemas. Não raramente as aulas iniciam e não vão até o final, e são 
frequentemente canceladas, por motivos de revista nas celas, por alerta de rebelião ou para o pagamento no "dia do pecúlio" 5 ".

Em razão desse ambiente que circunda a escola na prisão, o professor perde a autonomia sobre a sua turma, os alunos não têm uma sequência constante nos estudos e a coordenação pedagógica fica limitada na organização do currículo, que vem preestabelecido pelo MEC, sem autonomia de inferir no contexto do ambiente escolar da prisão.

Verificou-se que a PACH está bem equipada para atender os alunos no Programa EJA; mas, segundo as afirmações relatadas pelos sujeitos de pesquisa $(\mathrm{C} 1)$ e $(\mathrm{C} 2)^{6}$, há de se considerar que o aluno/preso, influenciado pelo ambiente da prisão, necessita de um tratamento diferenciado. Na visão de Penna (2012), a escola carcerária não é imune aos problemas da prisão, pelo fato de ser uma instituição correcional acima de tudo, e os indivíduos que ali se encontram não estão por vontade própria.

Mesmo com todos os seus entraves do ambiente prisional, a educação carcerária ainda representa, para os alunos/presos, uma oportunidade de concluir seus estudos e livrar-se do duplo estigma da educação tardia de jovens e adultos: o sentimento de inferioridade pela falta de formação básica que oportuniza o ingresso no mercado de trabalho. Para Feitosa (2011), há de ser superada essa visão assistencialista e compensatória que se tem da EJA, bem como o preconceito que a vê como modalidade de pouco prestígio social.

Por isso que dentre as ações pedagógicas e educacionais da penitenciária está a intenção de ampliação do atendimento escolar, com a reestruturação do programa EJA, que prevê ampliar o atendimento para o máximo de presos possíveis. Para o sujeito de pesquisa C1, "o caminho é longo, pois o criminoso não foi educado para a educação"; na maioria dos relatos, os detentos informam que faltou orientação da família para a importância da educação na sua vida social e profissional, ou seja, os pais não tiveram acesso a educação e, portanto, não incentivaram os filhos a estudar.

\section{Relações entre a condição de privação de liberdade e a concepção de educação formal}

As adversidades encontradas na escola da prisão são diferentes das encontradas em um ambiente escolar normal, pois na prisão a educação tem cunho disciplinar e tende a ser

\footnotetext{
${ }^{5}$ Dia em que o preso recebe sua remuneração pelo trabalho executado na prisão, com definições expressas na Lei de Execuções Penais, em seu Art. 29.

${ }^{6}$ Coordenador Educacional do CEJA de Chapecó.
} 
vista mais como uma obrigação legal para com o detento do que um meio de construção da sua cidadania. Segundo Foucault (2014), esse faz parte dos princípios que compõem as técnicas penitenciárias, sendo os demais princípios a correção, classificação, modulação da pena, trabalho, controle técnico da detenção e instituições anexas; e "a educação do detento é por parte (dever) do poder público, ao mesmo tempo uma precaução indispensável no interesse da sociedade e uma obrigação para com o detento" (FOUCAULT, 1987, p. 224).

Por outro lado, a escola prisional, mesmo estando inserida em uma instituição austera e disciplinar por essência, na visão dos presos é considerada um ambiente de refúgio, como afirma o sujeito de pesquisa $\mathrm{AP}^{7}$ : "a hora mais esperada é a hora de ser chamado para ir à escola"; para o sujeito de pesquisa AP2, “a escola, muda o jeito de pensar, é um espaço onde pode conversar de coisas diferentes"; para o sujeito de pesquisa AP3, “[...] as aulas passam rápido. A escola é um espaço de liberdade dentro da prisão.” Esses conceitos de escola são criados pelas concepções da vida escolar regular, o que Silva (2012, p. 116) traduz afirmando:

Em liberdade, o processo de escolarização faz parte do processo de socialização dos jovens e isso significa que há valores adicionais que se obtêm por meio do acesso e permanência na escola: amizades, afirmação da identidade, senso de pertencimento a grupos, ampliação do universo cultural, estabelecimento de relações sociais, namoro etc., coisas incessíveis para quem está preso.

Portanto, a escola prisional é um espaço onde o detento, mesmo preso, sente-se liberto e a proposta da educação se apresenta como um meio de recuperação. Mas precisa-se ter cuidado ao atribuir a recuperação dos criminosos somente à educação. Silva (apud, ADORNO, 1995) alerta que, ao se falar de escola, é preciso considerar a realidade extrapedagógica que impacta as atividades que ocorrem no interior da instituição escolar. Aqui se abandona a posição ingênua daqueles que acreditam poder alterar as estruturas sociais pela ação exclusiva da escola.

O quadro a seguir apresenta dados do perfil dos presos entrevistados quanto a sua condição como detento e como aluno.

Quadro 1 - Perfil do aluno/preso

\begin{tabular}{|l|l|l|l|}
\hline Esp./Sujeito da pesq. & AP1 & AP2 & AP3 \\
\hline Idade & 45 anos de idade & 29 anos de idade & 22 anos de idade \\
\hline
\end{tabular}

\footnotetext{
${ }^{7}$ AP1, AP2 E AP3 - Sujeitos de pesquisa que cumprem pena privativa de liberdade na PACH.
} 


\begin{tabular}{|c|c|c|c|}
\hline Tempo de condenação & 36 anos de condenação & 10 anos de condenação & 22 anos de condenação \\
\hline Tempo cumprido da pena & $\begin{array}{l}\text { Seis anos e três meses } \\
\text { de cumprimento da } \\
\text { pena }\end{array}$ & $\begin{array}{l}\text { Três nos de cumprimento } \\
\text { da pena }\end{array}$ & $\begin{array}{l}\text { Um ano e dois meses de } \\
\text { cumprimento da pena }\end{array}$ \\
\hline $\begin{array}{l}\text { Motivo de ter } \\
\text { interrompido os estudos }\end{array}$ & $\begin{array}{l}\text { Saiu de casa por ter } \\
\text { brigado com os pais }\end{array}$ & $\begin{array}{l}\text { Por causa das mudanças } \\
\text { frequentes da família }\end{array}$ & Por opção própria \\
\hline $\begin{array}{l}\text { Idade com que } \\
\text { abandonou a escola }\end{array}$ & 12 anos & 13 anos & 12 anos \\
\hline $\begin{array}{l}\text { Até que série estudou } \\
\text { fora da prisão }\end{array}$ & $\begin{array}{l}3^{\mathrm{a}} \text { série da Educação } \\
\text { Básica }\end{array}$ & $\begin{array}{l}3^{a} \text { série da Educação } \\
\text { Básica }\end{array}$ & $\begin{array}{l}3^{\mathrm{a}} \text { série da Educação } \\
\text { Básica }\end{array}$ \\
\hline
\end{tabular}

Fonte: dados de entrevista, Pesquisa PACH - MANFRIN, 2015/2016.

Percebe-se que todos os entrevistados abandonaram os estudos ainda na infância e por diversos motivos, possivelmente relacionados ao convívio familiar.

Considerando o motivo da evasão escolar e a idade em que ela ocorre, bem como o baixo nível de escolaridade em relação à idade, remete rever os métodos de avaliação formativa $^{8}$, realizada por profissionais da escola na Educação Infantil. No dizer de Hoffmann (2005), "nunca tantos se consideraram no direito de avaliar a prática avaliativa, apontando as ambivalências, as injustiças e as desastrosas consequências de ações impensadas e arbitrárias que, pressupostamente, se efetivam sob a etiqueta avaliação".

As consequências da inobservância de má formação escolar nas crianças e adolescentes pode refletir no discernimento dos valores sociais e consequentemente indução ao desvio comportamental do indivíduo, abrindo as portas para seu ingresso no mundo do crime.

Nas afirmações dos sujeitos de pesquisa (AP1, AP2 e AP3), as salas são muito boas e adequadas para o desenvolvimento das atividades escolares, mas deixam a desejar no que tange ao material complementar para estudos extraclasse e à biblioteca, que possui acervo defasado. Percebe-se também que os alunos/presos mais novos são mais exigentes quanto aos materiais disponibilizados pelo Programa EJA na PACH. Mesmo assim, para o sujeito de pesquisa AP3, "representa uma forma de dar sentido na vida, na prisão".

Para melhorar o conceito da escola prisional, onde o espaço, de certa forma, é inibidor, e o saber dentro dele também tem esse caráter, há de se construir um currículo baseado nas representações dos atores da educação carcerária que venha atender, de certa

\footnotetext{
8 “[...] visa orientar o aluno quanto ao trabalho escolar, procurando localizar as suas dificuldades para o ajudar a descobrir os processos que lhe permitirão progredir na sua aprendizagem. A avaliação formativa opõe-se à avaliação somativa que constitui um balanço parcial ou total de um conjunto de aprendizagens. A avaliação formativa se distingue ainda da avaliação de diagnóstico por uma conotação menos patológica, não considerando o aluno como um caso a tratar, considera os erros como normais e característicos de um determinado nível de desenvolvimento na aprendizagem.” (HADJI, C. A avaliação - regras do jogo: das intenções aos instrumentos. Portugal: Porto, 1994. Disponível em: < http://revista.fct.unesp.br/index.php/Nuances/article/viewFile/181/251>. Acesso em: 27 jan. 2016).
} 
forma, todos os envolvidos, para isso, o Plano Político Pedagógico - PPP precisa estar alinhado aos interesses específicos da educação prisional. Mas priorizando o verdadeiro objetivo da educação.

\section{A contribuição do programa EJA como ferramenta de reinserção social dos sentenciados}

O programa EJA se configura como ferramenta socioeducacional que oportuniza o acesso à educação, seguindo as determinações da LDB e do sistema penal; a educação carcerária, segundo a LEP (1984), é disponibilizada a todos os detentos, mas não é obrigatória.

Para os que optam por estudar, a escola prisional proporciona a oportunidade de qualificação profissional necessária para sua reintegração na sociedade. Apesar de o percentual de alunos/presos matriculados na escola carcerária ser relativamente baixo, mas o interesse pelo estudo entre os presos vem aumentado mesmo que modestamente nos últimos anos.

O interesse em frequentar a escola na prisão ainda se associa muito à remissão de pena e possibilidade de sair da cela, principalmente pela falta de perspectivas de vida em liberdade. Como afirma o sujeito de pesquisa $\mathrm{A} 1$ ", frequentemente ouve-se dos detentos "não adianta mesmo". No relato do sujeito AP2, que está matriculado no programa EJA desde 2011 e ainda frequenta o Ensino Fundamental, "se concluir logo os estudos não se pode mais sair da cela nos dias de aula".

O programa EJA funciona nesse emaranhado de configurações, onde, segundo relato do sujeito da pesquisa $\mathrm{C} 2$, há certa disparidade entre objetivos e prioridades quanto ao atendimento do aluno/preso. Na visão pedagógica do coordenador do CEJA de Chapecó, o preso é um aluno e precisa ser tratado como tal; para a coordenação de educação da $\mathrm{PACH}, \mathrm{o}$ aluno, acima de tudo, é um criminoso, portanto as questões de segurança sobrepõem-se às diretrizes da educação. Um dos agravantes para lidar com alunos/presos, é que na mesma classe podem estar inimigos jurados de morte sem que o professor tenha conhecimento disso, Como foi relatado pelo Sujeito de pesquisa $\mathrm{P} 3{ }^{10}$, "procuramos não saber da situação criminal dos alunos".

\footnotetext{
${ }^{9}$ Sujeito de pesquisa - Administrador da Penitenciária.

${ }^{10}$ Sujeito de Pesquisa - Professor do CEJA na PACH.
} 
Cobra-se da escola prisional o que não acontece na escola regular.

Escola, realmente, não podia ser aquilo. Escola não podia ser aquela coisa enfadonha, feia, triste, que metia medo às crianças. Não podia ter aquele aspecto de prisão, aquele rigor de cadeia. Escola devia ser um lugar agradável, cheio de atrativos, de encantos, de beleza, de alegria, de tudo que recreasse e satisfizesse o espírito. (CORREIA, 2011, p. 38).

Para lidar com essas situações, necessariamente, precisa ter um regimento diferenciado, das situações da escola regular, no entanto, em Santa Catarina ainda não existe o PPP para a educação carcerária, assim como a maioria dos estados brasileiros, mesmo que esteja definido em lei. Tanto o PPP como o Projeto Político Institucional - PPI é necessários para definir critérios educacionais seguindo as características, cultura e especificidades de cada ambiente. É a partir do PPI que se pode diagnosticar e definir ações em cada unidade. Mas, para que seja realmente implantado, deve ser fruto da reflexão do coletivo que assume posicionamentos, define e redefine o seu diferencial e os rumos institucionais. Por isso, todo o PPI é um ato político, e “[...] o ponto de partida de um projeto político-pedagógico tem de estar exatamente nos níveis de aspiração, nos níveis de sonho, nos níveis de compreensão da realidade e nas formas de ação e de luta dos grupos populares" (FREIRE; FAUNDEZ, 1985).

\section{CONSIDERAÇÕES FINAIS}

Quando se pensa sobre os sentidos da prática educativa na prisão remete a uma reflexão sobre as maneiras de agir desta instituição, a privação da liberdade, a punição e a relação com a educação e a escola. Aparentemente, educação e punição, se apresentam como opostos e como podem conviver juntos, enquanto a educação visa o desenvolvimento pleno, livre, crítico das pessoas. A punição funciona como ação repressiva, limitante e flagelante em termos educacionais. A maneira que podem ficar juntas é compreender a educação como um direito humano, mas para fazer sentido a educação na prisão como um direito humano, precisa ser assumida de forma conceitual, ou seja, calcada nos valores, nas atitudes, habilidades que fortalecem a educação como um direito.

Mais de três décadas se passou da definição das diretrizes educacionais que preveem o atendimento socioeducativo aos indivíduos privativos de liberdade sem mudanças significativas nos conceitos da educação carcerária, herança de um sistema com bases estruturalistas, onde os indivíduos, mesmo reagindo, se comportam de acordo com uma lógica social externa mais poderosa do que a vontade individual. Da mesma forma o sistema penal 
age na intencionalidade de recuperação, mas não desprende o conceito preestabelecido de punição pela violência, que, supostamente os presos são merecedores. Reflexo da utilização de modelos baseados nas prisões americanas.

Mesmo que Código Penal Brasileiro possua avanços significativos na aplicação de penas alternativas, sua flexibilidade é passível de equívocos, podendo até ser considerado, de certa forma muito brando e controverso em alguns aspectos que se referem a garantia dos direitos humanos e constitucionais em relação a aplicação das penas restritivas.

Essas disparidades partem de um legislativo que formula leis que atendam aos anseios da sociedade, em um sistema judiciário que atende aos interesses do Estado, a uma realidade que somente o sistema penal conhece em sua essência. Nesse sentido ao sistema penal é entregue o resultado de um problema gerado pela sociedade e pelo Estado, sendo incumbido de encontrar soluções por meio de ações socioeducacionais que regenerem o criminoso para devolvê-lo à sociedade. E assim sucessivamente quantas vezes forem necessárias.

A legislação se atém aos detalhes legais da oferta educacional na prisão, mas negligencia a operacionalização das ações pedagógicas da escola prisional, omitindo o fato de que o presídio é um ambiente com vocação primeira, de detenção e repressão. Essa realidade compromete a atuação docente influenciando no processo de conscientização do aluno/preso para importância da educação como um caminho para o autoconhecimento, aprimoramento e qualificação necessários para a reintegração social. Nesse sentido, afeta todo o processo ao qual a escola se propõe de formação da consciência crítica dos educandos.

Esse processo demanda de um plano político pedagógico específico, que em Santa Catarina, ainda não foi implantado. O impasse está na definição sobre as especificidades da educação prisional. Para alguns a educação no ambiente prisional requer um olhar atento em função das questões pedagógicas elaboradas a fim de suprir a necessidade de informação. Para outros, a educação prisional não deve ser tratada de maneira diferenciada, para evitar o estigma de uma segunda discriminação, haja vista que a educação deve ser igual em qualquer esfera educacional, divergindo apenas o ambiente em que estão inseridos. Com esse impasse, em Santa Catarina, a educação prisional continua sendo regida pelas diretrizes da Educação Básica regular.

Na penitenciária Agrícola de Chapecó, não é diferente, mesmo sendo uma unidade de referência em ações socioeducacionais, sua vocação como instituição prisional é cumprir as sentenças estabelecidas pelo judiciário, promovendo uma permanência do internado mais harmônica possível, garantindo a integridade dos envolvidos. A prisão em sua 
essência não tem vocação para educar porque há de se considerar o contexto da comunidade carcerária. Há de criar um método de leve em consideração um processo inverso, ou seja, da realidade da prisão para a formulação das leis. E as políticas públicas que atendam essa demanda, seja formuladas com a participação dos atores sociais envolvidos no processo educacional e prisional,

Desta forma as medidas socioeducacionais aliadas a uma proposta pedagógica podem criar um sistema correcional mais eficaz, como é o caso de um modelo inovador que está sendo desenvolvido com jovens infratores na cidade Jaboatão em Pernambuco, onde os adolescentes têm a oportunidade de refletir sobre sua conduta sem a presença de celas ou pavilhões, frequentam a escola todas as manhãs e, no restante do tempo, realizam oficinas, praticam esportes e vivem em casas acolhedoras que contam com salas temáticas de educação.

No campo, deparamo-nos com uma realidade em que os atores envolvidos na educação prisional diferem em seus modos de pensar, fazendo com que a proposta educacional na PACH seja vista por muitos como uma contribuição paternalista, em que não se percebe intenção de formação crítica do educando. Essa realidade refere-se às pessoas ligadas ao departamento de execuções e estão em contato direto com os internados: podem pensar que também elas estão diante de uma tarefa contraditória, pois precisam impor obediência aos internados e, ao mesmo tempo, dar a impressão de que os padrões humanitários estão sendo mantidos e os objetivos racionais da instituição estão sendo realizados.

Os docentes que atuam no programa EJA se deparam com o emaranhado dessas relações de poder existentes dentro e fora das celas, permanecendo inertes aos desígnios institucionais em um sistema que parece ser impenetrável. Com isso, a ação docente se submete aos conceitos de uma educação, cumpridora de uma matriz curricular preestabelecida.

\section{REFERÊNCIAS BIBLIOGRÁFICAS}

BRASIL. Resolução 03 de 11 de 11 de março de 2009. Conselho Nacional de Política Criminal e Penitenciária. Ministério da Justiça, 2009.

Constituição (1988). Constituição da República Federativa do Brasil. 21. ed. ampl. São Paulo: Saraiva, 1999. 
Lei $\mathrm{n}^{\circ}$ 9.394, de 20 de dezembro de 1996. Estabelece as diretrizes e bases da educação nacional. Diário Oficial [da República Federativa do Brasil], Brasília, DF, v. 134, n. 248, 23 dez. 1996.Seção I, p. 27834-27841.

Lei de Execuções Penais. Lei no 7.210 de 11 de julho de 1984.

CEE/SC - Conselho Estadual de Educação de Santa Catarina, resolução 110, de 28 e3 agosto de 2012. Dispõe sobre as Diretrizes operacionais para a oferta de educação para jovens e adultos em situação de privação de liberdade nos estabelecimentos penais do Estado de Santa Catarina. 2012.

CNJ - Conselho Nacional de Justiça. Novo Diagnóstico de Pessoas Presas no Brasil. Departamento de Monitoramento e Fiscalização do Sistema Carcerário e do Sistema de Execução de Medidas Socioeducativas - DMF, Brasília, 2014.

CORREIA, Viriato. Cazuza. 43. ed. São Paulo: IBEP, 2011.

DEPEN - Departamento Penitenciário Nacional. Levantamento Nacional de Informações Penitenciárias. INFOPEN, 2014. Disponível em:< http://www.justica.gov.br/noticias/mjdivulgara-novo-relatorio-do-infopen-nesta-terca-feira/relatorio-depen-versao-web.pdf $>$. Acesso em julho 2016.

FEITOSA, Sonia Couto Souza. Método Paulo Freire: A Reinvenção de um Legado / Sonia Couto Feitosa. 2 ed. Brasilia: Liber Livro Editora, 2011.

FOUCAULT, Michel. Vigiar e Punir: nascimento da prisão. Tradução Raquel Ramalhete. 42 ed. Petrópolis, Rio de Janeiro MOSCOVICI, Serge. A representação social da psicanálise. Rio de Janeiro: Zahar, 1978 Vozes, 2014.

FOUCAULT, Michel. Vigiar e Punir: nascimento da prisão. Tradução Raquel Ramalhete. 29 ed. Petrópolis, Rio de Janeiro. Vozes, 1987.

FREIRE, Paulo. Pedagogia do Oprimido / Paulo Freire. 58 ed. Ver e atual.. Rio de Janeiro: Paz e Terra, 2014.

. Pedagogia da Esperança. Rio de Janeiro: Paz e Terra, 2001.

FREIRE, Paulo; FAUNDEZ, Antônio. Por uma Pedagogia da Pergunta. Rio de Janeiro: Paz e Terra, 1985.

HOFFMANN, Jussara. Do pensar ao agir em avaliação. Porto Alegre: Mediação, 2005.

IBGE - Instituto Brasileiro de Geografia e Estatística, IBGE. Censo 2010. Disponível em:<censo2010.ibge.gov.br/noticias-censo?id+1\&idnoticia+2296\&t+censo-2010-mulheressão-mais-instruidas-que-homens-ampliam-nivel-ocupação\&view=noticia>. Acesso em: 15 fev. 2015.

LEI COMPLEMENTAR No 170, de 07 de agosto de 1998. Dispõe sobre o Sistema Estadual de Educação de Santa Catarina (SANTA CATARINA, 1998). 
LOPES, Hálisson Rodrigo; PIRES, Gustavo Alves de Castro; PIRES, Carolina Lins de Castro. Organização penitenciária e os tipos de estabelecimentos prisionais no Brasil. In: Âmbito Jurídico, Rio Grande, XVII, n. 120, jan 2014. Disponível em: <http://www.ambito-juridico.com.br/site/?n_link=revista_artigos_leitura\&artigo_id=14117>. Acesso em janeiro 2016.

LOURENÇO, Arlindo da Silva; ONOFRE, Elenice Maria Cammarosano. Espaço da Prisão e suas Práticas Educativas: Enfoques e perspectivas contemporâneas/organizadores: Arlindo da Silva Lourenço, Elenice Maria Cammarosano Onofre. São Carlos: EduFSCar, 2012.

MARTINS, Rosilene Maria Sólon Fernandes. Direito à Educação: aspectos legais e constitucionais. Rio de Janeiro: Letra Legal, 2004.

PENNA, Marieta Gouvêa de Oliveira. O espaço da Prisão e suas práticas educativas/Relações Sociais e Espaço Escolar na prisão: Limites e Possibilidades da Ação Educativa no Interior de Uma Penitenciária. São Carlos: EdUFSCar, 2012.

PIAGET, Jean. The Construction of Reality in the Child. New York: Ballantine Bocks, 1971.

PINHO, Marcelo Simões Serran de. Políticas de segurança pública : análise do campo no legislativo federal / Tese (doutorado) - Universidade Federal de Santa Catarina, Centro de Filosofia e Ciências Humanas. Programa de Pós-Graduação em Sociologia Política / Marcelo Simões Serran de Pinho ; orientador, Prof ${ }^{\circ}$. Dr. Erni Seibel - Florianópolis, SC, 2014.

SECRETARIA DE ESTADO DA EDUCAÇÃO - SED. Educação prisional cresce em Santa Catarina/ Edinéia Rauta Assessoria de Imprensa SED, 2013. Disponível em:< http://www.sc.gov.br/index.php/mais-sobre-educacao/12127-educacao-prisional-cresce-emsanta-catarina>. Acesso dia: $10 \mathrm{dez}$ de 2015.

SILVA, Roberto da. O espaço da prisão e suas práticas educativas: enfoques e perspectivas contemporâneas / organizadores: Arlindo da Silva Lourenço, Elenice Maria Cammarosano Onofre. Silvio dos Santos / Por uma Política Nacional de Educação para os regimes de Privação de Liberdade no Brasil. p. 81 - 118. São Carlos: EdUFSCar, 2012. 